\title{
内シャント作製術における血管攣縮の診断
}

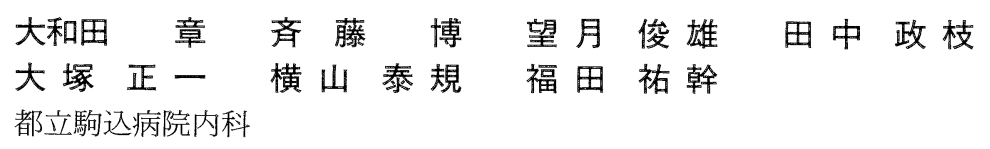

key words：慢性腎不全，内シャント作製術，橈骨動脈，血管攣縮，超音波ドップラー血流計

〈要旨〉

超音波ドップラー血流計を用いて, 内シャント作製術中に発生する橈骨動脈の攣縮の発生率および経時的変化を調 た。慢性腎不全の患者 14 例で, 原疾患は, 糖尿病 (DM) 4 例, DM以外 10 例であった。超音波ドップラー血流計 (8MHz) を用い, 術中, 経時的に, 血管吻合前, 吻合 5 分後, 10 分後, 20 分後に吻合部より $2 \mathrm{~cm}$ 近位部の橈骨動 派血流量を測定した。1 4 例中 5 例（36\%）で動静脈吻合 5 分後に著明な血流量の低下（吻合前值の $14.3 \pm 4.5 \%$ ）を

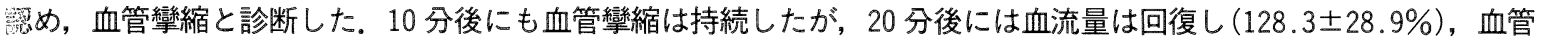
彎縮は消失した。血管攣縮 $(+)$ 群 5 例の内訳は DM 2 例, DM 以外 3 例で, DM が攣縮発生の risk factor とはい 苋なかった. 内シャント作製術中の血管攣縮と, その後の内シャントの開存の予後との関係については, 今後の検討 が必要と思われた。

結論として，超音波ドップラー血流計は，内シャント作製術中の血管攣縮の診断に有用であり，血管攣縮の発生率 は36\%で, 動静脈吻合 20 分後には消失した。

\section{Diagnosis of vasospasm during construction of arteriovenous shunts for hemodialysis}

Akira Owada, Hiroshi Saito, Toshio Mochizuki, Masae Tanaka, Masakazu Otsuka, Yasunori Yokoyama, Sukemoto Fukuda

Department of Internal Medicine, Tokyo Metropolitan Komagome Hospital

We investigated radial artery spasm occurring as a result of surgery to create arteriovenous (AV) shunts for hemodialysis.

Radial arterial blood flow was transcutaneously measured using a ultrasonic doppler flowmeter in 4 patients with diabetic renal failure and 10 patients with non-diabetic renal failure prior to construction of an AV shunt and 5 min, $10 \mathrm{~min}$ and $20 \mathrm{~min}$ after completing the shunt.

A significant decrease in arterial blood flow (to $14.3 \pm 4.5 \%$ of the initial value), indicating vasospasm, was observed 5 min after shunting in $5(36 \%)$ of the 14 patients. Althorgh vasospasm persisted for more than $10 \mathrm{~min}$, arterial blood flow was restored within $20 \mathrm{~min}(128.3 \pm 28.9 \%)$, implying that vasospasm had stopped. The 5 patients who developed vasospasm consisted of 2 diabetics and 3 non-dibetics. Diabetic patients were not predisposed to vasospasm according to the results of Fisher's analysis. Further follow-up is required to determine whether the occurrence of vasospasm is correlated with subsequent AV-shunt obstruction.

In conclusion, ultrasonic doppler flowmetry was useful in diagnosing vasospasm after surgical AV shunting. Vasospasm occurred in $36 \%$ of the patients and persisted up to $20 \mathrm{~min}$ after the procedure.

緒言 するが，血管吻合直後の急性閉塞の原因になりうると考

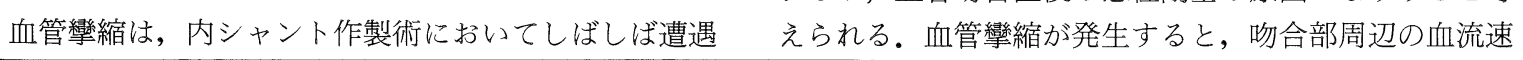
大和田 章 都立駒込病院内科 $\bar{T} 113$ 文京区本駒込 3-18-22 (03-3823-2101) 


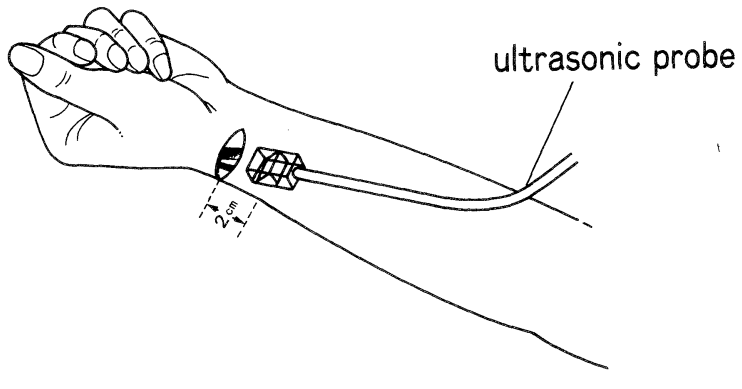

図 1 Ultrasonic doppler flowmetry

度が低下し，血栓形成を惹起しうるからである。内シャ ント作製術中の血管攣縮の診断については, 我々の調べ

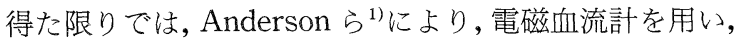
21 例中 10 例で血管攣縮を認めたという報告があるのみ である。

今回我々は, 超音波ドップラー血流計を用いて, 内シャ ント作製術中に発生する橈骨動脈の卛縮を定量的に診断 し，その発生率および経時的変化を認べた。

\section{対象および方法}

対象は，慢性腎不全の患者，14 例で，原疾患は，DM が 4 例 (男性 3 例, 女性 1 例, $62.8 \pm 6.6$ 歳), DM 以外 が 10 例（男性 3 例，女性 7 例，61.3土4.6 歳）で, DM 以外 10 例の内訳は，慢性腎炎 8 例，腎結核 1 例，良性腎 硬化症 1 例であった。

全例に対し，橈骨動脈と橈側皮静脈の側々吻合を施行 し，1）術中， 5 分間隔で，血圧，脈拍数を測定した。

2) 超音波ドップラー血流計（Hayashi Denki Co.）を 用い, 術中, 経時的に, 血管吻合前, 吻合 5 分後, 10 分 後, 20 分後に橈骨動脈血流量を測定した。

測定は, 図 1 に示すごとく, 吻合部より $2 \mathrm{~cm}$ 近位部 の橈骨動脈にて, 貼付型プローブ $(8 \mathrm{MHz})$ を用い, 同一 箇所で一定の照射角 $\left(60^{\circ}\right)$ にて経皮的に行った.

血流量は, Kasulke らの用いた式により，

血流量 $(\mathrm{m} l / \mathrm{min})=0.6 \mathrm{~V} \pi \mathrm{r}^{2}$

$(\mathrm{V}$; 流速, $\mathrm{cm} / \mathrm{s}, \mathrm{r}$; 血管半径, $\mathrm{mm}$ )で算出した。流 速は，超音波ドップラー血流計による実測值で，3 回測 定し, 平均值を求めた（図 2 ). 血管半径は, caliper 用い, 血管外径と壁厚を測定し, 血管半径 $=($ 血管外径一 壁厚×2）/2 の式で求めた。なお，動脈を切開している 吻合前と異なり，吻合後は，上式を用いて血管半径を計 算できないが, 血管平滑筋の収縮, 弛緩の程度はおそら く動脈血管径の数\%の変化で起こっていると考えら れ ${ }^{3)}$ ，吻合後の血管半径は吻合前と同一とした。なお，実 際, 我々の preliminary study でも, 血管外径は, 吻合 前と吻合後で不変であった。

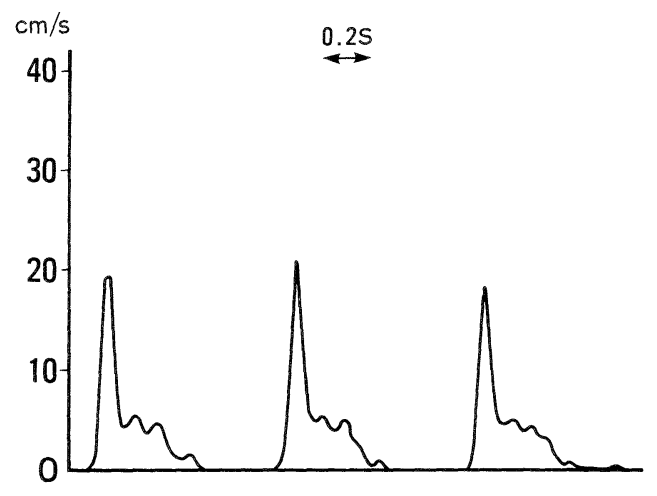

図 2 Blood flow velocity

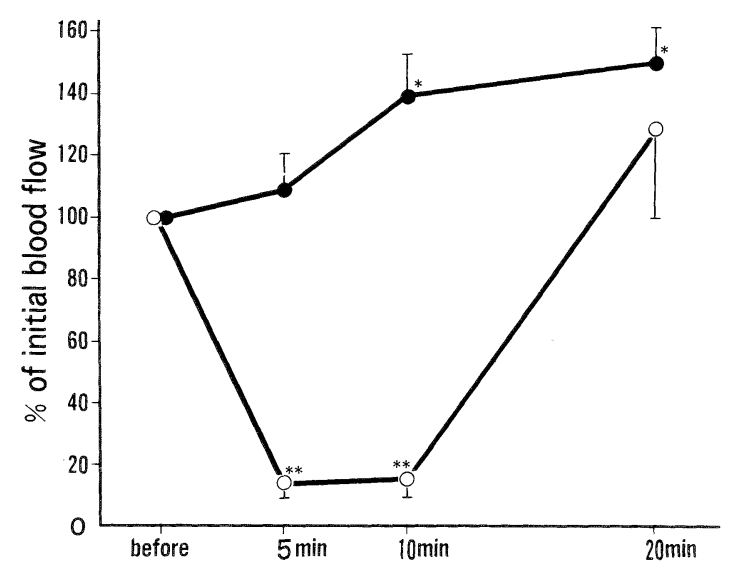

図 3 Blood flow of radial artery before and after construction of arteriovenous $(\mathrm{AV})$ anastomosis. $\operatorname{spasm}(-)(n=9), \bigcirc-\bigcirc$ spasm $(+)(\mathrm{n}=5)$. Values (means $\pm \mathrm{SE}$ ) are expressed as \% of blood flow before construction of $\mathrm{AV}$ anastomosis.

$* \mathrm{p}<0.05$ vs initial blood flow.

$* * \mathrm{p}<0.001$ vs initial blood flow.

統計解析は, Student's $t$ test を用い, $\mathrm{p}<0.05$ を有 意とした。

\section{結果}

図 3 に示すごとく，14 例中 5 例 $(36 \%)$ で動静脈吻合 5 分後に著明な橈骨動脈血流量の低下 (吻合前值の 14.3 土4.5\%, means $\pm \mathrm{SE}, \mathrm{p}<0.001$ vs 吻合前值）を認め, 血 管攣縮と診断した. 10 分後にも血管攣縮は持続したが (吻合前值の $16.0 \pm 6.2 \% ， \mathrm{p}<0.001 \mathrm{vs}$ 吻合前值)，20 分後には血流量は回復し $(128.3 \pm 28.9 \%, p>0.05 \mathrm{vS}$ 吻合前值)，血管攣縮は消失した。 
表 Patient profile

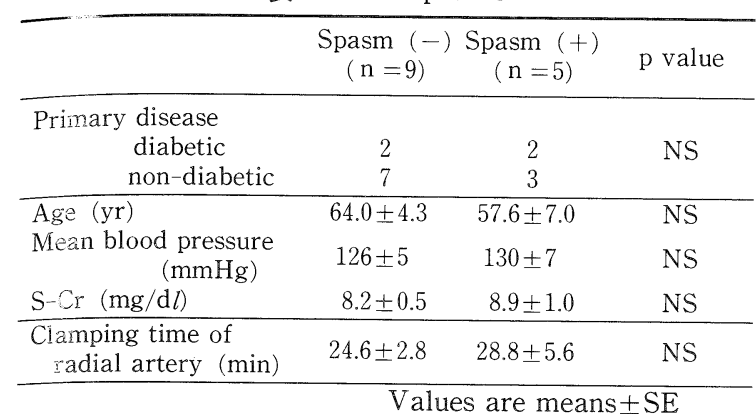

14 例中 9 例では血管攣縮は見られなかったが(図 3 ), 血管吻合 5 分後に吻合前值の $107.9 \pm 12.4 \%(p>0.05$

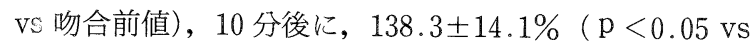
吻合前值)に血流量が増加しており, 吻合 20 分後にはさ らに $149.7 \pm 18.9 \%$ （ $\mathrm{p}<0.05$ vs 吻合前值）に増加して いた. 5 分後および 10 分後における, $\operatorname{spasm}(+)$ 群の 血流量は, spasm (一) 群に比し, 有意に低下していた $(\mathrm{p}<0.001)$.

表に血管攣縮 $(-)$ 群 $(\mathrm{n}=9)$ と血管攣縮 $(+)$ 群 $(\mathrm{n}=5)$ の patient profile を示す.

血管卛縮 (一) 群 9 例の内訳は DM 2 例, DM 以外 7 例で, 血管攣縮 (+) 群 5 例の内訳は DM 2 例, DM 以外 3 例で, Fisher 検定による解析で, 原疾患の内訳に つき, 両群間に有意差を認めなかった。すなわち, DM が 攣縮発生の risk factor とはいえなかった。

年齢, 術前平均血圧, 血清 $\mathrm{Cr}$ 值, 吻合術中の橈骨動 脈阻血時間についても両群間で有意差はなかった。

図 4 に示すごとく, 血管攣縮 (一) 群と血管攣縮 $(+)$ 群で, 吻合前, 吻合後の平均血圧の推移に有意な差を認 めなかった。

図 5 に示すごとく, 両群間で, 脈拍数にも有意差を認 めなかった。

\section{考察}

血管攣縮は, 異型狭心症における冠動脈や，クモ膜下 出血時の脳動脈に見られるが, 両者においては, 致死的 あるいは後遺症を残し大きな問題となる。 それに対し， 内シャント作製術中の橈骨動脈の血管攣縮は, 致死的で はないが，血流低下により，血栓形成を促進し，血管吻 合直後の急性閉塞の原因になりうると考えられる。吻合 が終了し，血流再開した後，thrill を触知できないのは， 1 つには，この血管攣縮によるものであり，術者を悩ま せることになる。

内シャント作製術中の橈骨動脈の血管攣縮の発生率に

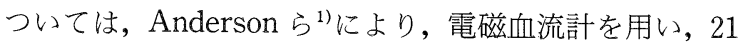
例中 10 例すなわち約 $50 \%$ で血管攣縮を認めたという報

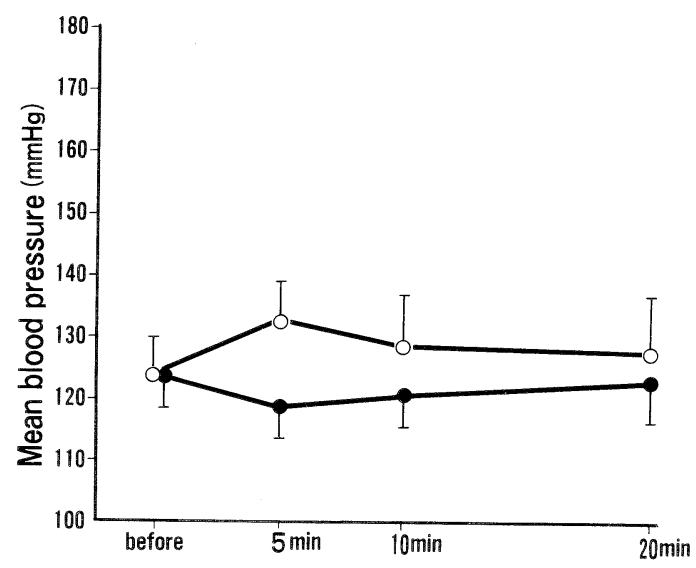

図 4 Mean blood pressure before and after construction of $\mathrm{AV}$ anastomosis. $-\operatorname{spasm}(-)(\mathrm{n}=9)$, $\bigcirc-\bigcirc \operatorname{spasm}(+)(\mathrm{n}=5)$. Values are means $\pm \mathrm{SE}$.

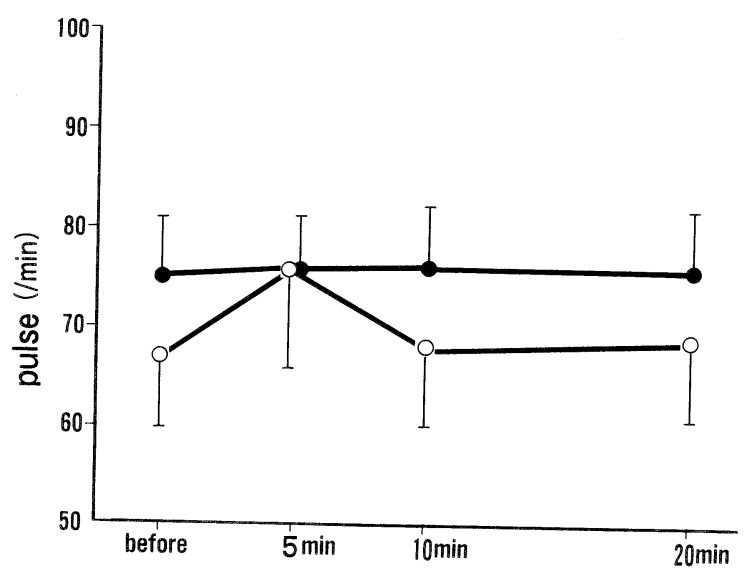

図 5 Pulse before and after construction of $\mathrm{AV}$ anastomosis. $(-)(\mathrm{n}=9), \bigcirc-\bigcirc \operatorname{spasm}(+)(\mathrm{n}=$ $5)$. Values are means $\pm \mathrm{SE}$.

告があるのみである. 彼らは橈側皮静脈の血流量を測定 しているが, 我々の結果と同様に, 攣縮は吻合 20 分後に は回復していた，攣縮時の血流量は，回復時の $50 \%$ 位で あり，それに対し，我々の studyでは血管攣縮における 血流量は吻合前値の $14.3 \%$ （回復時の $11.1 \%$ ）に低下し ていた。

橈骨動脈の血流量は，血管攣縮（一) 群で，10 分後に $138.3 \pm 14.1 \%, 20$ 分後に $149.7 \pm 18.9 \%$ と前值以上に増 加し，血管攣縮（+）群でも 20 分後に $128.3 \pm 28.9 \%$ と 増加しているが, これは主として, 橈骨動脈と橈側皮静 脈の shuntにより，末梢血管抵抗が減少し，心拍出量が 
増加したためと考えられる。

Anderson ら $ら^{1)}$ は, 慢性腎不全の原疾患別に攣縮の発生 率を分析していないが，我々の study では，DM で2例/ 4 例 $=50 \%, \mathrm{DM}$ 以外で 3 例 $/ 10$ 例 $=30 \%$ の発生率で,

Fisher 検定では DM が有意な risk factor とはならな かった。しかし，今後症例数をふやしていくと，血管病 変の強い DM の方が攣縮の発生率が高くなる可能性は 否定できないと考えられる。

血管攣縮の機序については, 冠動脈 ${ }^{4,5)}$, 脳動脈 ${ }^{6}$ の場合 は最近, 強力な血管収縮性ペプチドである endothelin の 関与が示唆されているが，橈骨動脈の挲縮の場合は，そ の機序についての報告はない.1つの可能性は，橈骨動 脈に対する機械的操作による,血管平滑筋の収縮である. もう 1 つの可能性は, 手術侵襲による血管内皮細胞の損 傷による内皮細胞由来の血管収縮性物質の放出であり, 今後の研究が必要である.

内シャント作製術中の血管攣縮と，その後の内シャン 卜の開存の予後との関係については, 症例数が 14 例と多 くないため，結論的なことはいえないが，短期的には明 確な関連は認めなかった。すなわち，血管攣縮を起こし た群で，直後に内シャントが閉塞する傾向はなかった。 しかし, 長期予後については今後の追跡が必要と考えら れた。

\section{結論}

1。超音波ドップラー血流計は，内シャント作製術中 の血管攣縮の診断に有用である。

2.血管攣縮の発生率は $36 \%$ で，慢性腎不全の原疾患 別では, DM は risk factor とは考えられなかった。

3. 血管攣縮は，動静脈吻合 10 分後まで観察され，20
分後には消失した。

4. 血管攣縮と内シャント開存の予後との関連につい ては，今後の検討が必要である。

本論文の要旨は, 第 36 回日本透析療法学会で発表した。

\section{文献}

1) Anderson CB, Etheredge EE, Harter HR, Graff RJ, Codd JE, Newton WT : Local blood flow characteristics of arteriovenous fistulas in the forearm for dialysis. Surg Gynecol Obstet 144 : 531-533, 1977

2) Kasulke RJ, Lichti EA, Kapsch DN, Silver D : Transcutaneous quantitation of arterial flow with ultrasound. Ann Surg 195 : 464-468, 1982

3）鈴木 光，今嶋達郎，松崎智子，本村廉明：血管攣 縮機能と内皮細胞. 臨床科学 $25: 989-994 ， 1989$

4) Toyo-oka $T$, Aizawa $T$, Suzuki N, Hirata $Y$, Miyauchi T, Shin WS, Yanagisawa M, Masaki T, Sugimoto $\mathrm{T}$ : Increased plasma level of endothelin-1 and coronary spasm induction in patients with vasospastic angina pectoris. Circulation 83 : 476-483, 1991

5) Luscher $\mathrm{TF}$ : Endothelin-Key to coronary vasospasm ? Circulation $83:$ 701-703, 1991

6) Masaoka H, Suzuki R, Hirata $Y$, Emori $T$, Marumo $\mathrm{F}$, Hirakawa $\mathrm{K}$ : Raised plasma endothelin in aneurysmal subarachnoid haemorrhage. Lancet ii : 1402,1989 